\title{
PRODUÇÃO DE FALA BILÍNGUE: AVALIANDO SIMILARIDADE LINGUÍSTICA, CUSTOS DE TROCA ENTRE LÍNGUAS E SISTEMA ATENCIONAL
}

\author{
Elena Ortiz-Preuss* \\ Universidade Federal de Goiás \\ Goiânia, GO, BR \\ Taiany Braz Rodrigues ${ }^{*}$ \\ Universidade Federal de Goiás/Capes \\ Goiânia, GO, BR
}

\begin{abstract}
Resumo
Este artigo apresenta um estudo que visou analisar efeitos da similaridade linguística e custos de troca em tarefas de avaliação de redes de atenção e de nomeação de figuras, dentro do paradigma de troca de línguas. O desempenho dos participantes, bilíngues português-inglês e português-espanhol, foi observado a partir de medidas de tempo de reação e acurácia das respostas nessas tarefas. Os resultados não mostraram diferenças significativas nas médias entre os grupos, mas nas comparações intrassujeitos foram observadas diferenças estatisticamente significativas quando os participantes tinham que trocar da L2 para a L1, evidenciando um custo de troca assimétrico. Também foram constatadas correlações entre as duas tarefas no grupo de bilíngues português-espanhol. Esses resultados são interpretados como indícios de efeitos da similaridade linguística nas tarefas de nomeação e de atenção.
\end{abstract}

Palavras-chave: Similaridade linguística; Custo assimétrico; Nomeação de figuras; Atenção; Bilinguismo.

\section{BILINGUAL SPEECH PRODUCTION: EVALUATING LINGUISTIC SIMILARITY, LANGUAGE SWITCHING COSTS AND ATTENTIONAL SYSTEM}

\begin{abstract}
This article presents a study which aimed at analyzing both linguistic similarity and switching cost effects on the attentional network task and picture-naming task, within the language-switching paradigm. Reaction time and accuracy of responses in these tasks were observed in bilingual Portuguese-English and Portuguese-Spanish participants' performances. The results did not show any significant differences in the means between the groups. On the other hand, in the within-subjects comparison, statistically significant differences were observed when the participants switched from the L2 to the L1, evidencing an asymmetrical switching cost. Some correlations were also found between the two tasks in the Portuguese-Spanish bilingual group. These results are interpreted as indications of linguistic similarity effects in both naming and attention tasks.
\end{abstract}

Keywords: Linguistic similarity; Asymmetric cost; Picture naming; Attention; Bilingualism.

\footnotetext{
${ }^{*}$ Professora Adjunto III da Universidade Federal de Goiás - UFG. Tem experiência na área de Letras, Linguística Aplicada, Psicolinguística, com ênfase em Língua Espanhola. Seus interesses de pesquisa são: aquisição de L2; bilinguismo; acesso lexical e produção de fala; cognição e instrução na aprendizagem de línguas. Seu e-mail é elena.ortizp@yahoo.com.br

** Estudante de mestrado do programa de Pós-Graduação em Letras e Linguística na Faculdade de Letras da UFG e bolsista CAPES. Graduou-se pelo curso de Letras - Espanhol na Universidade Federal de Goiás. Seu e-mail é taianybraz@hotmail.com
} 


\section{Introdução}

A produção de fala bilíngue envolve a ativação lexical de dois sistemas linguísticos (o da L1 e o da L2 ${ }^{1}$ ) e a seleção do léxico na língua-alvo. Sob essa perspectiva, é um processo que requer alto controle dos sistemas linguísticos, de modo a garantir a comunicação somente na língua pretendida, evitando interferências interlinguísticas e, consequentemente, problemas comunicativos. Vários pesquisadores têm levantado hipóteses sobre como se desenvolve o acesso lexical e a produção de fala bilíngue, supondo, por exemplo, que diferenças no nível de ativação ou a atuação do controle inibitório seriam responsáveis pela eficácia do processo (COSTA, 2005; 2006; GREEN, 1998; GROSJEAN, 2013; KROLL et al, 2008; MISRA et al, 2012).

Pesquisas dentro do paradigma de troca de línguas tentam elucidar como se desenvolve a produção de fala bilíngue. Nesses estudos, busca-se verificar a atuação de mecanismos inibitórios em tarefas de nomear figuras na L1 ou na L2, seguindo a pista da língua a ser feita a nomeação que é dada junto à figura (COSTA, HERNÁNDEZ e SEBASTIÁN-GALLÉS, 2008; COSTA, SANTESTEBAN e IVANOVA, 2006; COSTA e SANTESTEBAN, 2004; MEUTER e ALLPORT, 1999; PEETERS et al, 2014). Ou seja, o participante deve reconhecer a imagem e observar a pista para saber em que língua deve nomear a imagem. Nesse contexto, há situações de troca e não troca de língua que são avaliadas em termos de custos para a nomeação, isto é, se retardam ou aceleram o início da nomeação com cada uma das línguas (L1 ou L2). As principais evidências obtidas foram de custo de troca assimétrico (quando há diferença no tempo de resposta nos contextos de troca entre as línguas) e de custo de troca simétrico (quando não há diferença no TR nos contextos de troca).

Um aspecto pouco investigado nessa perspectiva foi o efeito da semelhança formal entre os dois sistemas linguísticos no processo de produção de fala bilíngue. Entretanto, a similaridade linguística tem se mostrado um complicador no uso da L2, porque pode motivar a ocorrência de fenômenos de interferência entre as línguas, os quais nem sempre são adequados. Sob essa perspectiva, o bilíngue deve estar atento para que o léxico selecionado seja de fato o da língua-alvo e não o que é bastante similar, mas na língua nãoalvo. Em outras palavras, o sistema de atenção, que forma parte da capacidade de controlar as línguas que estão constantemente ativadas, parece ser de grande importância para o bom desempenho bilíngue (COSTA, SANTESTEBAN e IVANOVA, 2006).

Em vista do exposto, o estudo apresentado neste artigo foi desenvolvido com o propósito de observar efeitos de similaridade linguística e de custos de troca na produção de fala de bilíngues ${ }^{2}$ português-inglês e português-espanhol, ao realizar tarefas de nomeação de figuras, na L1 ou na L2. Também foi avaliada a capacidade de atenção e seu papel na fala em L2 em tarefa de rede de atenção, cujos resultados foram correlacionados com o desempenho dos participantes na tarefa de nomeação.

Este artigo está organizado da seguinte maneira: primeiro, no referencial teórico, discutiremos brevemente o processo de produção de fala bilíngue e os custos de troca entre as línguas (simétrico e assimétrico), os efeitos da similaridade linguística na aquisição de L2 e a relação entre rede de atenção e bilinguismo; em seguida, no método, descreveremos os participantes, instrumentos $\mathrm{e}$ procedimentos de coleta de dados; posteriormente, nas análises, iremos expor e discutir os resultados; depois, nas considerações finais, destacaremos as principais contribuições do estudo; e, finalmente, listaremos as referências que fundamentam a pesquisa.

\section{Referencial Teórico}

\subsection{Processo de produção de fala bilíngue: os custos de trocas entre línguas}

A atuação eficiente de bilíngues em diferentes contextos comunicativos, ora na sua $\mathrm{L} 1$, ora na sua L2, tem sido o foco de muitos estudos que visam compreender quais mecanismos garantem que somente um dos sistemas linguísticos seja selecionado para a produção de fala. A esse respeito, e considerandose que ambos os sistemas estão permanentemente ativados em paralelo, conjectura-se que deve tratar-se de algo bastante eficiente, para garantir a manutenção 
da comunicação em somente uma das línguas, mas, ao mesmo tempo, não suficientemente intransponível para impedir a ocorrência de interferências interlinguísticas (COLOMÉ, 2001; COSTA, 2005; FINKBEINER, GOLLAN e CARAMAZZA, 2006; GROSJEAN, 2013; HERMANS et al, 2011; HOSHINO e THIERRY, 2011; KROLL et al, 2008; MISRA et al, 2012).

As pesquisas nessa temática têm apontado evidências favoráveis a diferentes hipóteses, ${ }^{3}$ dentre as quais destacamos: a hipótese de seleção não-específica, a qual pressupõe que diferenças no nível de ativação, em que a palavra pretendida na língua-alvo seria a mais ativada, garantiriam a seleção adequada, seja através de competição lexical (COLOMÉ, 2001; COSTA et al, 2003; HERMANS et al, 1998; HOSHINO e THIERRY, 2011; MISRA et al, 2012), seja sem competição (FINKBEINER, GOLLAN e CARAMAZZA, 2006); a hipótese de que a seleção é específica na língua-pretendida pressupõe que o léxico da língua não-alvo é ignorado pelos mecanismos de seleção (COSTA, MIOZZO e CARAMAZZA, 1999; COSTA e CARAMAZZA, 1999; COSTA, ALBAREDA e SANTESTEBAN, 2008; HERMANS, 2000; ROELOFS,1998); e a hipótese de controle inibitório, a qual prevê mecanismos que suprimem a ativação da língua não-pretendida, impedindo que nós lexicais dessa língua sejam considerados na seleção (COSTA e SANTESTEBAN, 2004; COSTA, SANTESTEBAN e IVANOVA, 2006; GREEN, 1998; GROSJEAN, 2013; KROLL, et al, 2008; MEUTER e ALLPORT, 1999; MISRA et al, 2012, PEETERS et al, 2014, ROELOFS, 1998).

Cabe mencionar que, embora essas hipóteses tenham sido corroboradas por diferentes pesquisas, elas ainda apresentam algumas lacunas. No caso das duas primeiras hipóteses, é necessário esclarecer a funcionalidade dos mecanismos que garantiriam a seleção da palavra-alvo na língua pretendida quando há várias palavras ativadas ao mesmo tempo. E no caso da terceira hipótese, é necessário elucidar que mecanismos poderiam garantir a inibição da língua não-alvo, haja vista que interferências entre as línguas são frequentemente observadas (COSTA, 2005; 2006; ORTIZ-PREUSS, 2011).

A respeito da terceira hipótese, atualmente, é amplamente difundida a concepção de que o acesso lexical bilíngue deve envolver algum tipo de mecanismo de controle de atenção, porque a troca de sistemas linguísticos é uma rotina para falantes bilíngues e, provavelmente, isso só seja possível devido à funcionalidade de mecanismos de controle inibitório em qualquer contexto conversacional. Estudos desenvolvidos dentro do paradigma de troca de línguas têm tido o propósito de avaliar o papel do controle inibitório na fala bilíngue. Nessas pesquisas, os participantes devem nomear figuras, na sua L1 ou na sua L2, conforme a pista que é dada, por exemplo, pela cor da figura. O desempenho é avaliado, principalmente, pelo tempo de reação ao nomear as figuras, em situações de troca e não troca entre as línguas. Os resultados obtidos nesses estudos têm apontado evidências do papel do controle inibitório na fala bilíngue e também de que essas trocas geram custos ao sistema de processamento, conforme o nível de proficiência do bilíngue (COSTA, HERNÁNDEZ e SEBASTIÁN-GALLÉS, 2008; COSTA, SANTESTEBAN e IVANOVA, 2006; COSTA e SANTESTEBAN, 2004; MEUTER e ALLPORT, 1999; PEETERS et al, 2014).

Dentre as evidências obtidas nessas pesquisas, consta que aprendizes com menos proficiência demoram mais para trocar da língua mais fraca (L2) para a língua mais dominante (L1) do que o contrário (COSTA e SANTESTEBAN, 2004; COSTA, SANTESTEBAN e IVANOVA, 2006; MEUTER e ALLPORT, 1999). Esse fenômeno, conhecido como custo de troca assimétrico, mostra que, para falar na L2, a L1 precisa ter sua ativação fortemente inibida; por isso, retornar a ela numa situação de troca de língua pode demorar mais. Por sua vez, para falar na L1, a L2 não precisa ser fortemente inibida, dessa forma, numa situação de troca de língua, pode ser mais rápido trocar da L1 para a L2. Em outras palavras, desfazer a inibição aplicada à L1, que é a língua mais dominante/ forte, é mais difícil do que desfazer a supressão da L2, que requer menos intensidade na inibição, por ser mais fraca. Por outro lado, estudos com bilíngues altamente proficientes mostraram custo de troca simétrico; ou seja, não houve diferença entre os tempos de reação se a tarefa requeria a troca para a L1 ou para a L2.

Um aspecto pouco contemplado nos estudos sobre o processo de produção de fala bilíngue é o impacto 
que a similaridade entre as línguas pode ter sobre os mecanismos de acesso e seleção lexical. Como se refere a um tema de interesse nesta pesquisa, trataremos disso com mais detalhe na próxima subseção.

\subsection{Similaridade linguística}

Diversos pesquisadores têm discutido os efeitos da similaridade linguística na aquisição de L2, tendo em vista que se trata de um processo subjetivo que pode resultar numa percepção equivocada ou parcial da realidade (JARVIS e PAVLENKO, 2008; RINGBOM e JARVIS, 2011; RINGBOM, 2007; ODLIN, 2003; ORTIZ-PREUSS, 2014). Os estudos com foco na similaridade linguística tratam de verificar se os aprendizes de L2 conseguem identificar, total ou parcialmente, pontos de similaridade entre as línguas e se consideram similares pontos que são dissimilares (RINGBOM e JARVIS, 2011). Isso significa que, com relação ao comportamento dos aprendizes, a similaridade pode ser total ou parcialmente percebida, pode ser equivocadamente suposta, ou, ainda, não ser notada.

Ringbom (2007) argumenta que efeitos da similaridade linguística funcionam de modo diferente entre as habilidades de compreensão e de produção. Enquanto na compreensão a forma das palavras já está dada, sendo necessário somente fazer o seu mapeamento semântico, na produção, é preciso dar a forma linguística adequada a uma intenção pré-verbal. O autor afirma, ainda, que é possível, em curto espaço de tempo, alcançar considerável nível de proficiência receptiva, ao passo que falar ou escrever numa língua similar é um pouco mais demorado e complexo, porque a produção envolve dois tipos diferentes de conhecimento: o declarativo, que se refere ao conhecimento do que (léxico e gramática), e o procedural, que se refere ao conhecimento do como (uso de regras e palavras em frases/situações comunicativas). Cabe ressaltar que o conhecimento procedural necessita de mais atividades de prática para se consolidar do que o saber declarativo.

Um dos aspectos que podem ser indícios do grau de similaridade linguística é o status cognato das palavras (ORTIZ-PREUSS, 2014), sendo que as cognatas são as mais similares entre as línguas, porque compartilham significado e forma (fonológica, morfológica e ou sintática), diferentemente das não cognatas, cuja estrutura formal é diferente (COSTA, LA HEIJ e NAVARRETE, 2006; ORTIZ-PREUSS, 2014). Nessa mesma linha, Ortiz-Preuss (2014) argumenta que o status cognato das palavras afeta o tempo de reação de bilíngues em tarefa de nomear figuras e que a similaridade linguística não garante maior acurácia e menor tempo de reação na produção de fala.

De acordo com Costa, Santesteban e Ivanova (2006), a similaridade linguística pode afetar o sistema de processamento de informações. Os autores argumentam que o acesso lexical bilíngue é uma situação de conflito entre duas respostas em línguas diferentes, sendo que somente uma delas deve ser selecionada. A facilidade de resolução desse conflito dependeria do grau de similaridade entre as representações lexicais ativadas em cada língua (a que deve ser ignorada e a que deve ser selecionada). Quanto mais similares forem as línguas, ou seja, quanto maior compartilhamento de traços houver entre elas, mais lento é o processo de seleção lexical e maior é a capacidade de atenção requerida (o que ficou conhecido como hipótese de sobrecarga atencional). Portando, segundo esses pesquisadores, "a similaridade entre as línguas pode afetar o modo como os bilíngues controlam sua fala" (COSTA; SANTESTEBAN; IVANOVA, 2006, p. 1059).

A hipótese de sobrecarga atencional, isto é, de que a similaridade pode afetar o funcionamento da rede de atenção, levantada por Costa, Santesteban e Ivanova (2006), fundamentados no efeito de interferência semântica, foi testada por eles em um experimento de nomeação de desenhos, dentro do paradigma de troca de línguas. No estudo, os participantes tinham que nomear figuras na L1 ou na L2 dependendo da cor da figura, que funcionava como uma pista sobre qual deveria ser a língua da nomeação. As análises não revelaram efeitos significativos de similaridade linguística no desempenho de troca de língua, no caso de bilíngues altamente proficientes, mas evidenciaram que o custo de troca assimétrico só ocorre em bilíngues menos proficientes; ou seja, o nível de proficiência pode diminuir o efeito de similaridade e a ocorrência 
de custo de troca assimétrico. Na próxima subseção iremos descrever brevemente como se constitui a rede de atenção, visto que é um construto diretamente relacionado com o desempenho linguístico bilíngue.

\subsection{Rede de atenção}

Conforme Schmidt (2001), a atenção é uma habilidade cognitiva complexa e seletiva, cuja capacidade é limitada, porque as pessoas não conseguem dispensar o mesmo grau de atenção a todos os estímulos a sua volta. Por sua vez, Eysenck e Keane (2007) argumentam que a atenção pode ser passiva ou ativa. A atenção passiva é controlada por estímulos externos (bottomup) e a atenção ativa é controlada pelas expectativas e objetivos do indivíduo (top-down). Além disso, estes autores mencionam que estudos vêm tratando de desvendar os mecanismos de atenção e sua capacidade, com vistas a conhecer os limites do processamento, bem como a natureza do processo de seleção. Esses estudos envolvem experimentos com vários estímulos, solicitando-se que o indivíduo responda somente sobre um deles, para que se possa observar o processo de atenção seletiva ou sobre todos os estímulos, para se conhecer a capacidade de processamento.

Com relação à natureza dos mecanismos de atenção, Posner e Petersen (1990) e Tomlin e Villa (1994) defenderam que a rede atencional abrangia sistemas neuroanatômicos de alerta, orientação e detecção. Posteriormente, Fan et al (2002), modificou um pouco essa descrição, propondo o modelo de rede de atenção mais difundido atualmente, o qual prevê três subsistemas interdependentes: 1) alerta: sistema encarregado da manutenção ou estado de vigilância; 2) orientação: sistema de seleção espacial ou do canal a ser atendido; e 3) controle executivo ou atenção executiva: sistema de resolução de conflito entre ações possíveis (COSTA, HERNÁNDEZ e SEBASTIÁN-GALLÉS, 2008; REDICK e ENGLE, 2006).

Seguindo esse modelo de rede de atenção, estudos têm evidenciado que o bilinguismo pode afetar o funcionamento da rede. Nessas pesquisas sobre atenção e bilinguismo, cada um dos sistemas da rede de atenção é avaliado, considerando que: no controle executivo, esperam-se respostas mais lentas na condição incongruente (em que há conflito entre estímulos que precisa ser resolvido) do que na congruente; no sistema de alerta, esperam-se respostas mais rápidas quando os estímulos são precedidos por uma pista, do que quando não há nenhuma pista; e no sistema de orientação, esperam-se respostas mais rápidas quando uma pista indica onde os estímulos irão aparecer do que quando não indica. Os resultados mostraram que bilíngues superaram monolíngues nas tarefas de atenção, sendo mais eficientes no sistema de alerta e de controle executivo, porque eram mais rápidos do que os monolíngues na condição incongruente e/ou quando os estímulos vinham acompanhados de uma pista de alerta (COSTA, HERNÁNDEZ e SEBASTIÁN-GALLÉS, 2008; COSTA et al, 2009; COSTA, SANTESTEBAN e IVANOVA, 2006; COSTA e SANTESTEBAN, 2004; HERNÁNDEZ et al, 2010; REDICK e ENGLE, 2006).

Conforme a discussão teórica exposta, similaridade linguística, trocas entre línguas e mecanismos de atenção podem ser aspectos inter-relacionados e que influenciariam a produção de fala bilíngue. Entretanto, essas inter-relações são ainda pouco abordadas nas pesquisas, razão pela qual propomos o presente estudo, o qual será descrito na próxima seção.

\section{Método}

\subsection{Participantes}

Este estudo contou com uma amostra de 17 participantes, divididos em dois grupos, conforme a sua L2: inglês ou espanhol. O grupo de bilíngues portuguêsinglês era composto por 07 participantes, sendo 02 do sexo feminino e 05 do sexo masculino, com média de idade de 21,14 anos ( $\mathrm{DP}=1,57)$. O grupo de bilíngues português-espanhol era composto por 10 participantes, sendo 07 do sexo feminino e 03 do sexo masculino, com 30,7 anos de média de idade ( $\mathrm{DP}=13,59)$. Todos os participantes estavam no $6^{\circ}$ semestre de seus respectivos cursos de línguas (L2). Cabe esclarecer que os cursos possuem uma carga horária semanal de 3 horas e 20 minutos de aula e que cada semestre corresponde a 60 horas/aula, portanto, esses participantes podem ser 
considerados bilíngues tardios que já tiveram mais de 180 horas-aula de L2.

No questionário de histórico linguístico, os participantes informaram com que idade iniciaram seu processo de aquisição da L2, e constatou-se que o tempo médio transcorrido desde o início da aquisição no grupo de bilíngues português-espanhol é de 13,2 anos $(\mathrm{DP}=11,19)$ e no grupo de bilíngues portuguêsinglês é de 5,28 anos $(\mathrm{DP}=1,11)$. Isso significa que a correspondência entre o início da aquisição da L2 nem sempre é equivalente ao início do referido curso e que houve casos em que o estudo da L2 foi interrompido e posteriormente retomado.

Além disso, embora o tempo de estudo e experiência linguística indiquem que os participantes possuem um nível de proficiência $^{5}$ intermediário-avançado, foi solicitado no questionário que os participantes indicassem, numa escala de 1 a 6 (sendo 1=muito baixo; 2 =baixo; 3 =regular; $4=$ bom; $5=$ =muito bom; e $6=$ proficiente), seu nível de domínio da L2, abrangendo as quatro habilidades linguísticas (ler, escrever, ouvir e falar). Nessa autoavaliação, constatou-se que no grupo de bilíngues português-espanhol a média foi de 4,4 pontos ( $\mathrm{DP}=0,75)$ e no grupo de bilíngues português-inglês foi de 4,42 anos ( $\mathrm{DP}=0,82)$; ou seja, os participantes reportaram ter um bom domínio linguístico na L2.

Finalmente, salientamos que a participação neste estudo foi voluntária e, após terem recebido os esclarecimentos necessários, os participantes assinaram o Termo de Consentimento Livre e Esclarecido, em conformidade com o protocolo de pesquisa aprovado pelo CEP/UFG (número CAAE 23328113.7.0000.5083).

\subsection{Instrumentos}

\subsubsection{Questionário de histórico linguístico}

Este questionário tinha o propósito de obter informações úteis para delinearo perfil dos participantes, tais como: idade, sexo, tempo de aquisição da L2, autoanálise do nível de domínio das línguas. Para isso, foi feita uma adaptação do Questionário de Avaliação de Proficiência e Experiência Linguística/LEAP-Q, de Marian, Blumenfeld e Kaushanskaya (2007).

\subsubsection{Tarefa de nomeação de desenhos}

Nesta tarefa, o objetivo era avaliar as nossas hipóteses sobre os efeitos da similaridade linguística e custos de troca na nomeação de figuras, as quais previam que: 1) as nomeações seriam mais rápidas e acuradas no grupo de bilíngues português-inglês do que entre os bilíngues português-espanhol, devido ao diferenciado grau de similaridade entre os pares de línguas envolvidos; e 2) os tempos de reação (TR) seriam mais altos nos contextos de troca para a L1 do que para a L2, devido ao fenômeno de custo de troca assimétrico.

Para isso, o experimento foi desenvolvido no software E-prime 2.0, com 30 imagens, sendo 15 correspondentes a substantivos concretos, cognatos e 15 não $\operatorname{cognatos}^{6}$ (conforme Quadro 1), as quais deveriam ser nomeadas na L1 ou na L2 dos participantes, conforme a pista da língua que era dada pela cor da moldura em que a imagem estava inserida. Se a moldura era azul, o participante tinha que nomear na L1, se a moldura era vermelha, a nomeação deveria ser feita na L2. As figuras eram divididas em blocos que poderiam conter de 2 a 10 imagens. Cada bloco tinha o mesmo número de figuras correspondendo a vocábulos cognatos e não cognatos. Dessa forma, cada imagem aparecia 4 vezes no experimento, sendo 2 vezes nomeada na $L 1$ e 2 vezes nomeada na L2; ou seja, metade das nomeações (60) eram feitas na L1 e a outra metade na L2, perfazendo um total de 120 nomeações. 
Quadro 1 - Vocábulos usados no experimento

\begin{tabular}{c|c|c|c|c|c}
\hline \multicolumn{2}{c|}{ Cognatos } & \multicolumn{3}{c}{ Não cognatos } \\
\hline Português & Espanhol & Inglês & Português & Espanhol & Inglês \\
\hline prato & plato & plate & coruja & búho & owl \\
\hline cangurú & canguro & kangaroo & colher & cucharra & spoon \\
\hline tênis & tenis & tennis & abacaxi & ananá & pineapple \\
\hline limão & limón & lemon & garfo & tenedor & fork \\
\hline girafa & jirafa & giraffe & bolacha & galleta & cracker \\
\hline camelo & camello & camel & peru & pavo & turkey \\
\hline diamante & diamante & diamond & cabide & percha & hanger \\
\hline elefante & elefante & elephant & isqueiro & encendedor & lighter \\
\hline leão & león & lion & melancía & sandía & watermelon \\
\hline pinguim & pinguino & penguin & morango & frutilla & strawberry \\
\hline castelo & castillo & castle & abóbora & calabaza & pumpkin \\
\hline tomate & tomate & tomato & óculos & gafas & glasses \\
\hline anjo & ángel & angel & cadeira & silla & chair \\
\hline brócolis & brócoli & broccoli & guarda-chuva & paraguas & umbrella \\
\hline barril & barril & barrel & berço & cuna & cradle \\
\hline
\end{tabular}

Cabe mencionar que a ordem de apresentação das figuras era contrabalanceada e que os nomes, em português, espanhol e inglês, foram estatisticamente controlados em termos de frequência e extensão. Para o controle das frequências foram consultados os seguintes sites com bancos de dados disponíveis: $<$ http://corpusbrasileiro.pucsp.br/cb/Acesso.html>, para vocábulos em português; <http://corpus.rae.es/ creanet.html $>$, para vocábulos em espanhol; e <http:// corpus.byu.edu/glowbe $>$, para vocábulos em inglês. Para o controle de extensão, tomou-se como parâmetro o número de sílabas das palavras em cada uma das línguas. A Tabela 1 apresenta as médias e desvio padrão de frequência e extensão.

Tabela 1 - Médias e desvio padrão da frequência e extensão das palavras
A condição crítica neste estudo, isto é, o contexto de troca ou não troca entre as línguas, foi controlada nos intervalos entre os blocos. Ao longo do teste havia 10 situações de troca de línguas (sendo 5 da L2 para a L1 e 5 da L1 para a L2) e 9 situações de não troca de língua (sendo 4 em que se mantinha na L1 e 5 em que se mantinha na L2).

O experimento tinha uma etapa de aquecimento, com 10 figuras a serem nomeadas tanto na L1 quanto na L2, para que os participantes pudessem se familiarizar com a tarefa e sanar possíveis dúvidas previamente.

O desempenho dos participantes foi avaliado quanto à acurácia e ao tempo de resposta $\left(\mathrm{TR}^{7}\right)$, os quais eram registrados pelo E-prime 2.0, instalado em um computador Notebook Sony Vaio VPCSB, 13.3".

\begin{tabular}{l|l|c|c}
\hline \multicolumn{2}{c|}{ Descrição } & $\begin{array}{c}\text { Frequências } \\
\text { Média (DP) }\end{array}$ & $\begin{array}{c}\text { Extensão } \\
\text { Média (DP) }\end{array}$ \\
\hline \multirow{3}{*}{ Cognatas } & Português & $3856,73(4305,84)$ & $2,53(0,516)$ \\
\cline { 2 - 4 } & Espanhol & $1447,53(1419,74)$ & $2,53(0,516)$ \\
\cline { 2 - 4 } & Inglês & $18237,27(13862,41)$ & $2,20(0,561)$ \\
\hline \multirow{3}{*}{ Não-cognatas } & Português & $4650,07(6433,71)$ & $3,00(0,756)$ \\
\cline { 2 - 4 } & Espanhol & $960,40(1443,64)$ & $2,73(0,704)$ \\
\cline { 2 - 4 } & Inglês & $15999,93(18783,57)$ & $2,07(0,884)$ \\
\hline
\end{tabular}




\subsubsection{Tarefa de rede de atenção (ANT task)}

Nesta tarefa, tínhamos o objetivo de avaliar a capacidade atencional dos participantes e associá-la ao seu desempenho na tarefa de nomeação de figuras. Este experimento também foi desenvolvido no E-prime 2.0, conforme a descrição feita por Costa, Hernández e Sebastián-Gallés (2008), em que o participante era solicitado a responder o mais rápido e corretamente possível para que lado estava apontando a flecha central de uma sequência de flechas. Foram previstos 96 ensaios igualmente divididos em 12 condições, com o propósito de abranger os subsistemas que compõem a rede de atenção, a saber: alerta, orientação e controle executivo. O sistema de alerta era avaliado por meio do fornecimento de uma pista central $\left(^{*}\right)$, antes do estímulo-alvo; o sistema de orientação era avaliado pelo efeito da pista espacial, indicando (acima ou abaixo do ponto de fixação $[+]$ ) onde a sequência iria aparecer na tela do computador; e o sistema de controle executivo era avaliado por meio da análise do desempenho na condição incongruente (quando a flecha central apontava para uma direção diferente das outras $[\rightarrow \rightarrow \leftarrow \rightarrow \rightarrow]$ ) em comparação com a condição congruente (quando as flechas apontavam para o mesmo lado $[\rightarrow \rightarrow \rightarrow \rightarrow \rightarrow]$ ) e a condição neutra (quando a flecha-alvo não estava cercada por outras flechas [$-\rightarrow-[]$ ). Conforme mencionado anteriormente, a condição incongruente é a que se relaciona diretamente com o controle executivo, porque implica uma situação de conflito que precisa ser resolvida.

Portanto, nesta tarefa, as condições combinavam o tipo de pista (central, dupla, com pista ou sem pista) e o tipo de estímulo (congruente, incongruente, neutro). Um dos objetivos era testar as seguintes hipóteses:

1. as respostas seriam mais rápidas quando havia uma pista (central), do que sem pista;

2. as respostas seriam mais rápidas quando havia uma pista (espacial) que indicava o local em que os estímulos apareceriam, do que quando havia uma pista neutra (dupla);
3. as respostas seriam mais lentas na condição incongruente do que na congruente.

O experimento incluía uma etapa de treinamento, para que os participantes pudessem se familiarizar com a tarefa e sanar possíveis dúvidas. As respostas dos participantes foram registradas, em termos de acurácia e tempo de reação (TR), no software E-prime 2.0, instalado em um computador Notebook ASUS X202E, 11,6".

\subsubsection{Procedimentos}

Inicialmente, foi feito o convite aos participantes, prestando-lhes os devidos esclarecimentos sobre o estudo, e solicitando-lhes que assinassem o TCLE. Em seguida, os participantes receberam o questionário para preencher com suas informações pessoais e o histórico linguístico. Posteriormente, os participantes viram um powerpoint das figuras emolduradas (da mesma forma como apareceriam na tarefa de nomeação, conforme Figuras 1 e 2) e com seus respectivos nomes na L1 e na L2, abaixo da moldura, para garantir que os participantes reconheceriam as imagens, e evitar que os resultados pudessem ser afetados por desconhecimento lexical, comprometendo, assim, as análises dos custos de processamento. Cabe mencionar que houve apenas 4 casos de participante que manifestou não saber até 2 palavras da lista na L2, o que não consideramos ser quantia suficiente para afetar os resultados da pesquisa.

Figura 1- Apresentação português-espanhol

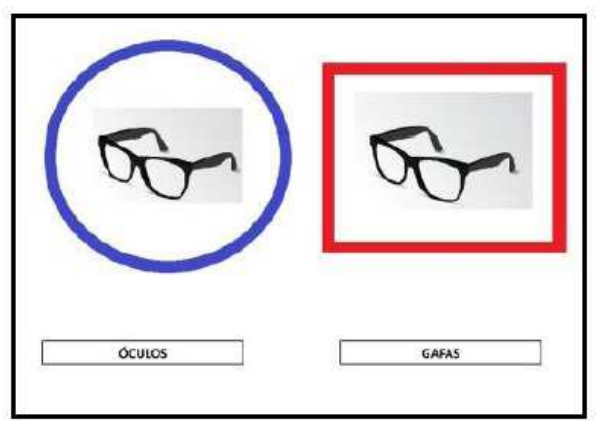


Figura 2 - Apresentação português-inglês

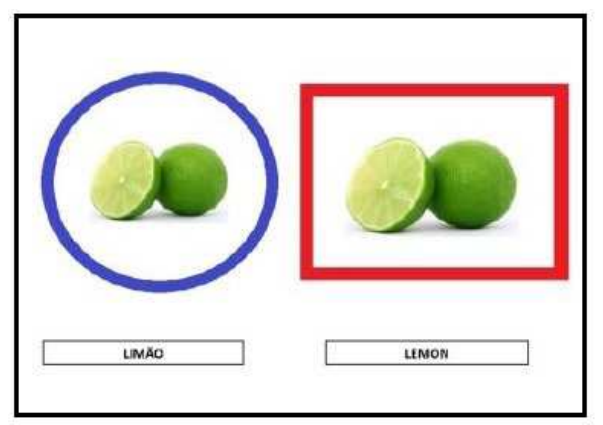

Após essa etapa de reconhecimento, os participantes realizaram as tarefas de nomeação de figuras e de rede de atenção, respectivamente. Ao todo, a realização das tarefas demorou, em média, 8 minutos.

Depois de finalizadas as coletas, teve início a tabulação dos dados, por meio do aplicativo chamado E-merge, que integra o E-prime, o qual gerou planilhas de Excel, contendo as médias e desvio padrão da acurácia e TR dos participantes nas duas tarefas. Os dados do questionário também foram tabulados em planilhas de Excel. Em seguida, foram feitas análises estatísticas exploratórias, inferenciais e de correlação, por meio do uso do software SPSS 1.8, as quais serão expostas na próxima seção.

\section{Análise dos dados}

\subsection{Tarefa de nomeação de imagens}

Nesta tarefa pretendíamos verificar se as nomeações seriam mais rápidas e acuradas no grupo de bilíngues português-inglês do que nos bilíngues portuguêsespanhol e se os tempos de reação (TR) seriam mais altos nos contextos de troca para a L1 do que para a L2. Nas análises dos TR e acurácia, os dados foram tabulados com base nos seguintes tópicos: dados gerais das nomeações (Nomeação_Geral); dados específicos das nomeações em cada língua (Nomeação L1 e Nomeação L2); resultados das nomeações, considerando o status cognato das palavras em cada língua (CL1, CL2, NCL1, NCL2); dados gerais dos contextos de troca entre as línguas (Troca_Geral); dados específicos das trocas para cada uma das línguas (Troca para L1 e Troca para L2); resultados gerais nas condições de não troca (Não troca Geral); e resultados específicos nas condições de não troca, em cada língua (Não troca - L1 e Não troca - L2).

Os dados de média e desvio padrão (DP) dos grupos, na tarefa de nomeação de figuras, estão expostos na Tabela 2.

Tabela 2 - Resultados da tarefa de nomeação de figuras

\begin{tabular}{llcccc}
\hline & \multicolumn{2}{c}{ Espanhol $(\mathrm{N}=10)$} & \multicolumn{2}{c}{ Inglês(N=07) } \\
& Média & DP & Média & DP \\
\hline Nomeação Geral & 1015,73 & 230,74 & 939,55 & 151,62 \\
Nomeação L1 & 1000,43 & 221,97 & 985,46 & 173,65 \\
Nomeação L2 & 1006,82 & 240,00 & 881,25 & 131,32 \\
TR & 960,90 & 227,41 & 884,15 & 155,93 \\
& CL1 & 915,56 & 214,48 & 826,58 & 122,98 \\
CL2 & 1041,66 & 235,51 & 1087,89 & 97,47 \\
NCL1 & 1062,78 & 245,45 & 966,73 & 162,90 \\
NCL2 & 738,90 & 286,16 & 609,85 & 388,29 \\
& Troca Geral & 800,50 & 427,23 & 712,65 & 420,48 \\
Troca para L1 & 677,30 & 198,46 & 507,05 & 452,98 \\
Troca para L2 & 610,68 & 307,18 & 563,10 & 258,99 \\
Não troca Geral & 625,90 & 325,55 & 761,21 & 304,44 \\
Não troca - L1 & 595,46 & 345,36 & 365,00 & 286,32 \\
\hline Não troca - L2 & & & & \\
\hline
\end{tabular}




\begin{tabular}{clcccc}
\hline & & & & \\
Nomeação Geral & 79,30 & 22,03 & 58,28 & 35,94 \\
Nomeação L1 & 39,60 & 15,62 & 38,28 & 15,95 \\
Nomeação L2 & 33,20 & 16,77 & 29,28 & 15,72 \\
Acurácia & CL1 & 19,90 & 8,47 & 19,14 & 7,94 \\
& NC2 & 18,30 & 9,20 & 16,28 & 7,25 \\
& NCL1 & 19,70 & 7,45 & 19,14 & 8,11 \\
& NCL2 & 14,90 & 8,31 & 13,00 & 9,12 \\
& Troca Geral & 7,70 & 1,41 & 7,85 & 1,46 \\
& Troca para L1 & 4,70 & 0,48 & 4,71 & 0,48 \\
& Troca para L2 & 3,00 & 1,15 & 3,14 & 1,57 \\
& Não troca Geral & 7,50 & 1,41 & 6,71 & 2,05 \\
& Não troca - L1 & 3,50 & 0,70 & 3,85 & 0,37 \\
Não troca - L2 & 3,70 & 1,25 & 3,28 & 1,70 \\
\hline
\end{tabular}

Nota:DP = desvio padrão; CL1 = Cognata em nomeação na L1; CL2 = Cognata em nomeação na L2;

NCL1 = Não-cognata em nomeação na L1; NCL2 = Nãocognata em nomeação na L2.

Numa análise preliminar, conforme a Tabela 2, os tempos de resposta dos bilíngues português-inglês foram menores do que dos bilíngues portuguêsespanhol, na maioria dos contextos. As únicas duas exceções, em que os TR do grupo de espanhol foram mais rápidos, referem-se à nomeação: 1) de não cognato na L1 (NCL1) (M=1041,66), e 2) em contexto de não troca, seguindo na L1 $(M=625,90)$. Por outro lado, o grupo de espanhol foi o que teve médias de acurácia mais altas, sendo superado pelo grupo de inglês somente em quatro casos: 1) na média geral das trocas (Troca Geral, $M=7,70$ ), 2) nas trocas para a $\mathrm{L} 1$ $(M=4,70), 3)$ nas trocas para a $L 2(M=3,00)$, e 4) nas não-trocas com continuidade na L1 $(\mathrm{M}=3,50)$. Outro aspecto interessante dos resultados é que no grupo de espanhol as nomeações na L1 $(\mathrm{M}=1000,43)$ foram mais rápidas do que na $\mathrm{L} 2(\mathrm{M}=1006,82)$. Diferentemente, no grupo de inglês, as nomeações na L2 foram mais rápidas $(\mathrm{M}=881,25)$ do que na $\mathrm{L} 1(\mathrm{M}=985,46)$.

As análises estatísticas mostraram que os dados estavam numa distribuição normal, de acordo com os testes de Kolmogorov-Smirnov e Shapiro-Wilk, e que não houve diferença significativa nas comparações de médias entre os grupos. Por outro lado, foram constatados vários dados significativos nas análises intrasujeitos, por meio de Teste $\mathrm{T}$ pareado.
O primeiro dado significativo é que o grupo de bilíngues português-inglês foi o que apresentou mais diferenças significativas na acurácia e tempo de resposta. Este grupo apresentou maior correção das respostas com nomes não cognatos na L1 (NCL1) do que na L2 (NCL2) $(\mathrm{t}(6)=2,524, \mathrm{p}=0,045)$. Foi mais acurado também ao fazer nomeações na L1 do que na $\mathrm{L} 2(\mathrm{t}(6)=2,519, \mathrm{p}=0,045)$. Houve mais respostas corretas em contexto de não-troca, mantendo-se na L1, do que em contextos de troca para a L1 $(\mathrm{t}(6)=-6,000, \mathrm{p}=0,001)$. A acurácia também foi maior em contextos gerais de troca do que de não-troca $(t(6)=-2,489, \mathrm{p}=0,047)$ neste grupo.

Quanto aos tempos de resposta, observamos que o grupo de bilíngues português-inglês apresentou menores latências de nomeação, ou seja, foi mais rápido, quando as palavras eram cognatas do que quando eram não-cognatas, tanto na $\mathrm{L} 1 \quad \mathrm{t}(6)=-5,930, \mathrm{p}=0,001)$, quanto na $\mathrm{L} 2(\mathrm{t}(6)=-3,764, \mathrm{p}=0,009)$. Isso mostra que o status cognato pode estar interferindo no desempenho dos participantes, afetando o processamento em termos de TR. Além disso, o grupo também apresentou menores TR em contextos de troca para a L2 do que para a L1 $(t(6)=3,683, p=0,010)$. Esses resultados podem estar evidenciando que a L1 é dominante no grupo de inglês, 
por isso precisa ser fortemente inibida, aumentando, assim, o TR nesse caso, o que corrobora a hipótese de custo de troca assimétrico, discutida anteriormente.

Por sua vez, o grupo de bilíngues portuguêsespanhol apresentou menos dados significativos estatisticamente, os quais abrangiam somente escores de acurácia. Constatamos que as respostas eram mais acuradas nos contextos de troca para a L1 do que para a L2 $(t(9)=5,075, p=0,001)$. A acurácia também era maior em contextos de troca para a L1 do que nos contextos de não-troca, mantendo-se na L1 ( $\mathrm{t}(9)=-6,000, \mathrm{p}=0,000)$. Igualmente, nos contextos de não-troca, seguindo na L2, as respostas eram mais corretas do que quando era necessário trocar para a L2 $(\mathrm{t}(9)=2,333, \mathrm{p}=0,045)$. Cabe ressaltar que os resultados deste grupo evidenciaram certa insegurança com a L2 e dependência da L1, que pode ter motivação na similaridade entre as línguas, uma vez que os aprendizes são mais acurados nas situações de troca para a L1 do que para a L2.

É importante salientar que, embora nenhuma dessas diferenças entre os grupos tenha sido significativa estatisticamente, elas apontam uma tendência de comportamento compatível com a hipótese de sobrecarga atencional. Os bilíngues portuguêsespanhol, talvez, em virtude da similaridade entre as línguas, demoraram mais para responder e, em geral, alcançaram maior acurácia, enquanto os bilíngues português-inglês tendiam a ser mais rápidos, mas sua acurácia só foi maior nas situações de conflito, em que é preciso trocar a língua de nomeação, e nos casos de não-troca, seguindo com a L1. Em outras palavras, os participantes do grupo de inglês foram mais eficientes nas tarefas mais cruciais (de troca ou não), o que pode ter sido consequência da menor similaridade entre as línguas, e os bilíngues português-espanhol demoraram mais tempo para responder e, assim, garantiram maior acurácia. Sob essa perspectiva, as trocas entre línguas envolvendo português e espanhol parecem gerar mais conflito cognitivo, retardando a nomeação, do que as que envolvem português e inglês.

Os resultados mostram também que os dois grupos evidenciaram que a troca da L2 para a L1 foi mais lenta do que da L1 para a L2, o que é compatível com a hipótese do custo de troca assimétrico, segundo a qual a fala bilíngue requer que mecanismos inibitórios atuem fortemente sobre o sistema da L1, fazendo com que esse sistema seja mais difícil de ser acessado (COSTA e SANTESTEBAN, 2004; COSTA, SANTESTEBAN e IVANOVA, 2006; MEUTER e ALLPORT, 1999). Além disso, a latência de nomeação nos contextos de nãotroca foi menor quando se mantinha a nomeação na L2 do que quando se mantinha a nomeação na L1.

No Gráfico 1, está ilustrado o desempenho dos participantes nos contextos de troca e não-troca de línguas. As médias de TR do grupo de bilíngues português-inglês foram menores do que as do grupo de bilíngues português-espanhol, sendo que os contextos de troca requereram mais tempo dos participantes. Ressaltamos que os custos de troca correspondentes às diferenças entre as médias de TR nos contextos de troca e não-troca foram de 128,22 milissegundos, no grupo de bilíngues português-espanhol e de 46,75 milissegundos, no grupo de bilíngues portuguêsinglês, mas essa diferença também não foi significativa estatisticamente.

Gráfico 1 - Tempos de reação nos diferentes contextos de nomeação

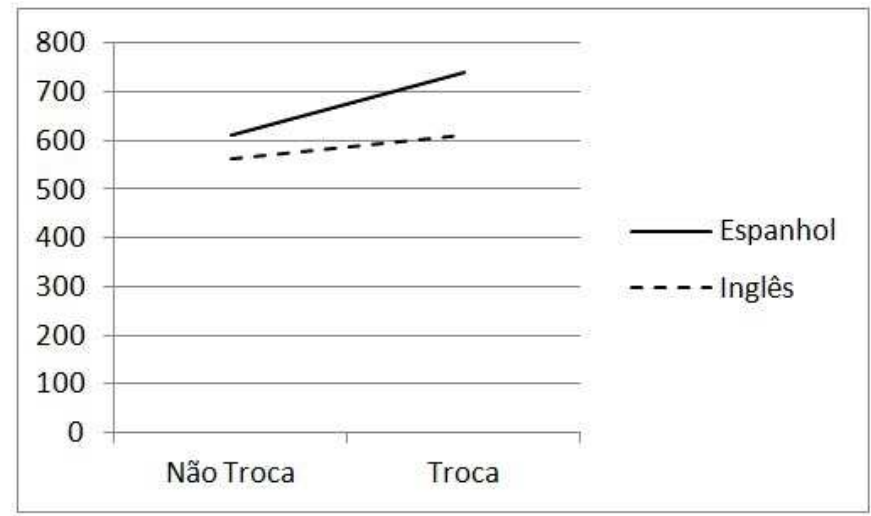

No Gráfico 2, está exposto o comportamento dos aprendizes nos contextos de troca para a L1 e para a L2. Nota-se que os TR do grupo de bilíngues português-inglês são menores do que os do grupo de bilíngues português-espanhol, independente da língua de troca. Mas o destaque desse caso é o custo de troca, correspondente à diferença entre as médias dos contextos de troca para a L1 e de troca para a L2, sendo de 123,20 milissegundos no grupo de espanhol 
e de 205,6 milissegundos no grupo de inglês (este último, como exposto anteriormente, foi significativo estatisticamente).

Gráfico 2 - Tempos de reação nos contextos troca entre as línguas

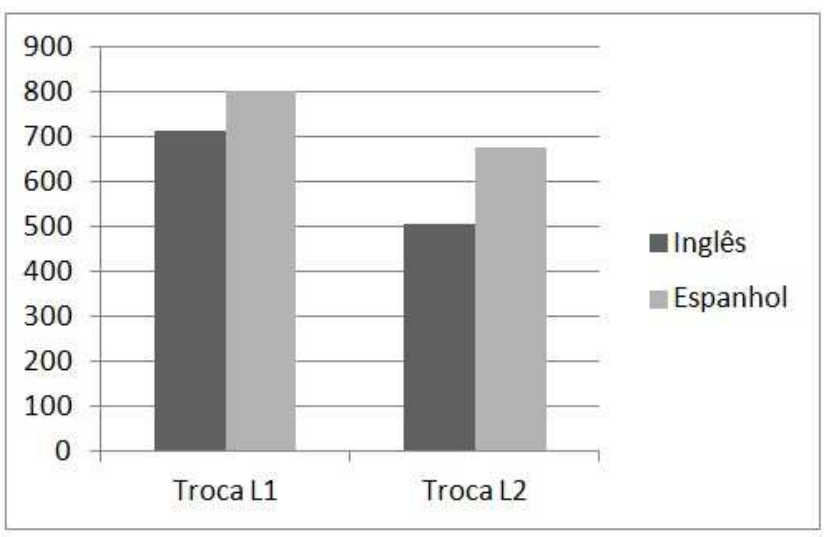

Em síntese, nosso estudo mostrou que, em geral, as nomeações mais rápidas e acuradas foram as do grupo de bilíngues português-inglês, embora as diferenças entre os grupos não tenham sido significativas estatisticamente. Os resultados também evidenciaram custo de troca assimétrico, sendo, inclusive, significativo estatisticamente no grupo de bilíngues portuguêsinglês. Na próxima seção passaremos a analisar os dados obtidos nos testes de atenção.

\subsection{Tarefa de rede de atenção (ANT)}

Na tarefa de atenção havia 12 condições que combinavam tipo de pista (central, dupla, com pista ou sem pista) e tipo de estímulo (congruente, incongruente, neutro), para que se pudesse verificar se as respostas seriam mais rápidas quando havia uma pista (central) do que quando não se dava nenhuma pista; se as respostas seriam mais rápidas quando havia uma pista indicando onde apareceriam os estímulos (espacial) do que quando a pista era neutra (dupla); e se as respostas seriam mais lentas na condição incongruente do que na congruente. Em vista disso, nas análises dos TR e acurácia, os dados foram tabulados com base nos seguintes tópicos: resultados gerais; dados específicos de cada condição de tipo de estímulo (congruente, incongruente e neutro) e de cada condição de tipo de pista (espacial, dupla, central e sem pista). Cabe mencionar que as condições de estímulo servem para avaliar o sistema de controle executivo, as condições de pista espacial ou neutra são utilizadas para avaliar o sistema de orientação e as condições central ou sem pista são empregadas para avaliar o sistema de alerta.

Os dados de média e desvio padrão (DP) dos grupos na tarefa de rede de atenção estão expostos na Tabela 3.

Tabela 3 - Resultados da tarefa de rede de atenção

\begin{tabular}{llcccc}
\hline & \multicolumn{2}{c}{ Espanhol } & \multicolumn{2}{c}{ Inglês } \\
& Média & DP & Média & DP \\
\hline \multirow{2}{*}{ Acurácia } & Acurácia Geral & 90,20 & 9,49 & 92,29 & 3,98 \\
& Congruente & 31,80 & 0,42 & 31,43 & 0,78 \\
& Incongruente & 27,20 & 8,40 & 29,57 & 2,14 \\
& Neutra & 31,20 & 1,54 & 31,29 & 1,49 \\
& Espacial & 0,93 & 0,11 & 0,94 & 0,03 \\
& Dupla & 0,93 & 0,92 & 0,98 & 0,01 \\
& Central & 0,94 & 0,09 & 0,97 & 0,04 \\
& Sem Pista & 0,94 & 0,10 & 0,94 & 0,08 \\
\hline \multirow{3}{*}{ TR } & & & & \\
& TR Geral & 620,56 & 147,87 & 510,30 & 57,77 \\
& Congruente & 605,22 & 165,30 & 497,80 & 72,48 \\
& Incongruente & 683,71 & 179,83 & 545,81 & 58,27 \\
& Neutra & 598,14 & 127,89 & 488,22 & 57,34 \\
& Espacial & 585,65 & 124,43 & 523,55 & 78,25 \\
& Dupla & 594,54 & 94,33 & 532,00 & 68,65 \\
& Central & 594,01 & 138,96 & 486,44 & 66,98 \\
& Sem Pista & 618,07 & 117,84 & 539,42 & 67,44 \\
\hline
\end{tabular}


De acordo com a Tabela 3, nos testes de atenção (ANT), os bilíngues português-inglês apresentaram menor tempo de resposta em todas as condições e maior acurácia em quase todas as condições testadas (a exceção é na congruente, cuja média foi levemente inferior ao grupo de bilíngues português-espanhol, $\mathrm{M}=31,43)$.

Nas análises de comparação de médias entre os grupos, as diferenças não se mostraram significativas estatisticamente. Mas houve evidências significativas nas comparações de médias intrasujeitos. $\mathrm{O}$ Teste $\mathrm{T}$ pareado mostrou que o grupo de inglês teve respostas mais acuradas na condição congruente do que na incongruente $(\mathrm{t}(6)=2,635, p=0,039)$; na condição neutra do que na incongruente $(\mathrm{t}(6)=-4,768, \mathrm{p}=0,003)$; e nos contextos de pista dupla do que de pista espacial $(\mathrm{t}(6)=-$ $0,009, \mathrm{p}=0,018)$. Além disso, este grupo demorou mais para responder na condição incongruente do que na neutra $(\mathrm{t}(6)=3,401, \mathrm{p}=0,014)$ e quando os estímulos eram precedidos de pista central do que sem pista $(\mathrm{t}(6)=-4,070, \mathrm{p}=0,007)$.

Por sua vez, o grupo de espanhol respondeu mais rápido na condição congruente do que na incongruente $(\mathrm{t}(9)=-2,318, \mathrm{p}=0,046)$; na condição neutra do que na incongruente $(\mathrm{t}(9)=3,368, \mathrm{p}=0,008)$; e quando os estímulos eram precedidos de pista espacial do que sem pista $(\mathrm{t}(9)=-2,624, \mathrm{p}=0,028)$.

No Gráfico 3, pode-se observar que nas condições incongruentes, onde havia conflito entre os estímulos, os TR mais baixos, do grupo de espanhol, correspondem aos contextos em que se deu pista, principalmente espacial, mas no grupo de inglês, os TR menores ocorreram quando havia pista espacial ou não havia pista; ou seja, para este grupo não é qualquer pista que tem potencial de interferir no desempenho.
Gráfico 3 - Tempos de reação nas diferentes condições do teste de rede de atenção

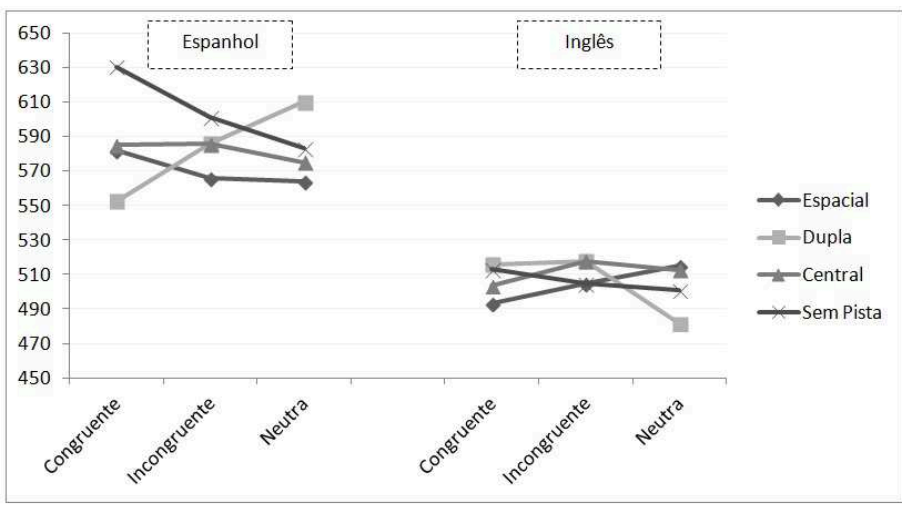

Em suma, os dados mostram que todas as hipóteses quanto ao funcionamento da rede de atenção foram corroboradas neste estudo, garantindo, assim, a confiabilidade e validade dos dados para que possamos realizar associações entre a tarefa de atenção e o desempenho dos participantes na tarefa linguística de nomeação de imagens, que serão expostas a seguir.

\subsection{Correlações entre as tarefas de nomeação de figuras e de rede de atenção (ANT)}

A fim de observar se haveria associação entre efeitos de similaridade linguística nas tarefas de nomeação e de atenção, foram realizados testes de correlação de Pearson, considerando-se que a condição de troca de línguas poderia ser equivalente à condição incongruente no ANT e que a condição de não-troca entre línguas poderia ser equivalente à condição congruente. Foram feitos testes de correlação tanto de acurácia quanto de tempo de reação, os quais apontaram que no grupo de bilíngues português-inglês não houve nenhuma associação significativa entre as variáveis supra mencionadas. No grupo de bilíngues portuguêsespanhol, entretanto, constatamos correlação positiva entre a acurácia na condição de não-troca de línguas e a acurácia na condição congruente do ANT ( $\mathrm{r}=0,671$, $\mathrm{p}=0,034)$. Também detectamos correlação negativa entre a acurácia da condição de troca de línguas e o tempo de reação do teste de atenção $(r=-0,774, \mathrm{p}=0,009)$ no grupo de espanhol. 
Conforme pode ser visualizado na Figura 3, a correlação positiva revela que os maiores escores de acurácia nas condições de não-troca correspondem aos maiores escores de acurácia na condição congruente do ANT. Portanto, esse resultado pode ser um indício do papel da atenção no desempenho linguístico de bilíngues de línguas similares, como português e espanhol.

Figura 3 - Correlação entre acurácia na condição de não-troca entre línguas e acurácia no teste de atenção na condição congruente - Bilíngues português-espanhol

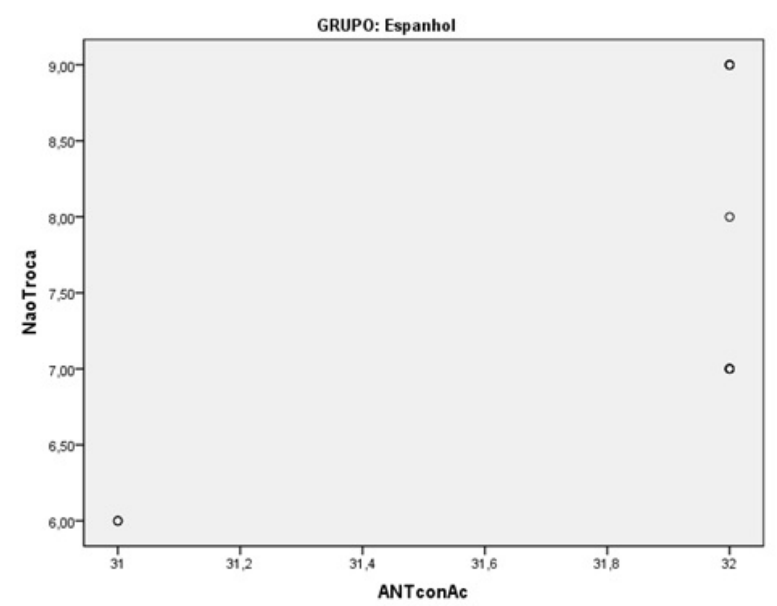

A Figura 4 ilustra a correlação negativa entre a acurácia da condição de troca de línguas e o tempo de reação do teste de atenção. Isso significa que os maiores escores de tempo de reação na condição congruente correspondem aos menores escores de acurácia na condição de troca de línguas. Cabe destacar que a situação de troca envolve um conflito que precisa ser resolvido, por isso pode demorar mais e ser menos acurada, mas a condição congruente é exatamente o oposto, porque não há conflito; logo, as respostas deveriam ser mais rápidas e mais acuradas. Em vista disso, essa correlação negativa parece ser um indício de que a similaridade nem sempre equivale à facilitação $\mathrm{e}$ que o modo como o aprendiz percebe essa similaridade pode interferir no seu desempenho. Em outras palavras, os participantes parecem não querer se deixar guiar pela ilusão da semelhança e dispensam mais atenção e tempo para responder, de modo a garantir mais acurácia, inclusive, nos contextos de congruência.
Figura 4 - Correlação entre acurácia na condição de troca de línguas e tempo de reação no teste de atenção na condição congruente - Bilíngues português-espanhol

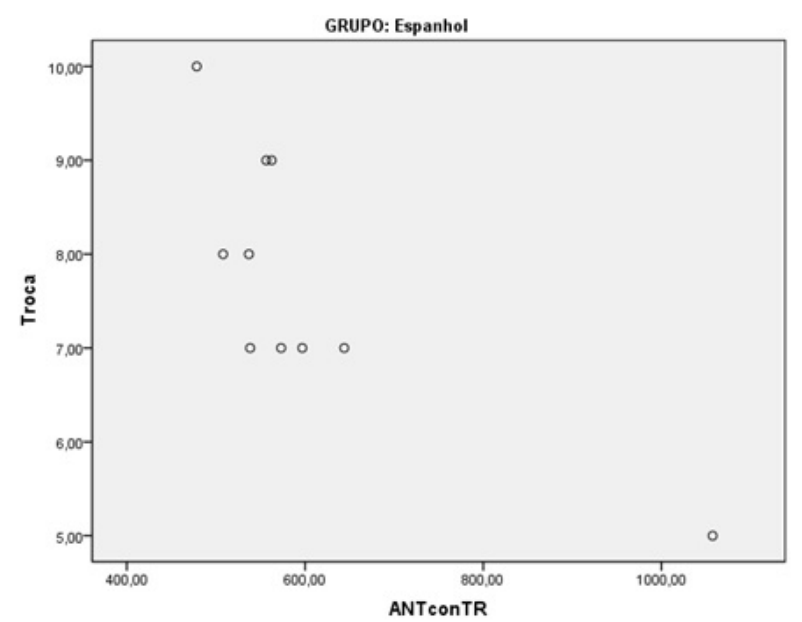

A nossa lógica de considerar equivalentes as condições congruentes e incongruentes e de troca e não-troca parece encontrar respaldo nesses resultados. Além disso, cabe destacar que esses dados sugerem que, no caso de bilinguismo envolvendo línguas mais similares, a funcionalidade dos mecanismos de atenção pode exercer efeitos no desempenho linguístico dos bilíngues.

\section{Considerações Finais}

O presente artigo expôs os resultados de uma pesquisa que visou observar efeitos de similaridade linguística e de custos de troca, em bilíngues portuguêsespanhol e português-inglês, os quais foram solicitados a realizar uma tarefa de nomeação de figuras, na L1 ou na L2, e outra de rede de atenção.

Os resultados gerais das duas tarefas não apontaram diferenças significativas entre os grupos. Entretanto, nas análises intrasujeitos, na tarefa de nomeação de figuras, constatamos custo de troca assimétrico, ou seja, diferença significativa estatisticamente entre as médias do tempo de reação dos bilíngues português-inglês, que demoravam mais para trocar para a L1 do que para a L2, e na acurácia dos participantes do grupo de bilíngues português-espanhol nos contextos de troca para a L1 do que para a L2. Além disso, no grupo de bilíngues português-espanhol, foram constatadas correlação 
positiva entre a acurácia na condição de não-troca de línguas e a acurácia na condição congruente do ANT, e correlação negativa entre a acurácia da condição de troca de línguas e o tempo de reação do teste de atenção.

Esses resultados são interpretados como indícios de efeitos da similaridade linguística nas tarefas de nomeação e de atenção. Entretanto, é importante ampliar a amostra, envolvendo bilíngues de diferentes níveis de proficiência, a fim de refinar as análises, bem como poder ratificar e dimensionar a magnitude desses efeitos.

Finalmente, é importante destacar que esses resultados são de grande relevância para os estudos sobre produção de fala bilíngue, pois contribuem para elucidar esse processo, ao levantar mais evidências do papel de mecanismos cognitivos como atenção e controle inibitório no acesso e seleção lexical.

\section{Notes}

1. As siglas L1 e L2 correspondem, respectivamente, aos conceitos de primeira língua ou língua materna e segunda língua ou língua estrangeira.

2. A concepção de bilinguismo que norteia este estudo é ampla, abrangendo aprendizes ainda em processo de aquisição da L2.

3. Devido ao escopo deste estudo, não foi feita uma discussão mais profunda dessas hipóteses, sugerindose ao leitor interessando a consulta aos artigos citados entre parênteses.

4. Tradução nossa para: Language similarity may also affect the way bilinguals control their speech.

5. Não foi feito ou solicitado teste específico para medir a proficiência dos participantes. Somente considerou-se seu histórico linguístico e autoavaliação.

6. Neste estudo baseamo-nos em Costa, Caramazza e Sebastián-Gallés (2000) que, desde uma perspectiva sincrônica, consideram cognatos os vocábulos com formas fonológica e ortográfica similares, e não cognatos são vocábulos cujas formas fonológica e ortográfica são diferentes.

7. O tempo de reação ou tempo de resposta (TR) é medido em milissegundos.

\section{Referências}

COLOMÉ, Àngels (2001). Lexical Activation in bilinguals' speech production: language-specific or languageindependent? Journal of Memory and Language, 45, 721-736.
COSTA, Albert (2005). Lexical Access in Bilingual Production. In: KROLL, Judith F. DE GROOT, Annette M.B. (Ed.). Handbook of bilingualism: Psycholinguistic Approaches. Oxford: Oxford University Press, pp. 308325.

(2006). Speech Production in Bilinguals. In: BHATIA, Tej K.; RITCHIE, William C. (Ed.). The Handbook of bilingualism. Oxford: Blackwell Publishing Ltd, pp. 201-223.

COSTA. Albert; HERNÁNDEZ, Mireia; COSTA FAIDELLA, Jordi; SEBASTIÁN-GALLÉS, Nuria (2009). On the bilingual advantage in conflict processing: now you see it, now you don't. Cognition, 113. Elsevier, 135-149.

COSTA. Albert; HERNÁNDEZ, Mireia; SEBASTIÁNGALLÉS, Nuria (2008). Bilingualism aids conflict resolution: Evidence from the ANT task. Cognition, 106. Elsevier, 59-86.

COSTA. Albert; ALBAREDA, Bárbara; SANTESTEBAN, Mikel (2008). Assessing the presence of lexical competition across languages: Evidence from the Stroop task. Bilingualism: Language and Cognition, 11(1). Cambridge: Cambridge University Press, 121-131.

COSTA, Albert; LA HEIJ, Wido; NAVARRETE, Eduardo (2006). The dynamics of bilingual lexical access. Bilingualism: Language and Cognition, 9 (2). Cambridge: Cambridge University Pres, 137-151.

COSTA, Albert; SANTESTEBAN, Mikel; IVANOVA, Iva (2006). How do highly proficient bilinguals control their lexicalization process? Inhibitory and languagespecific selection mechanisms are both functional. Journal of Experimental Psychology: learning, memory and cognition, 32 (5). American Psychological Association, 1057-1074.

COSTA, Albert; SANTESTEBAN, Mikel (2004). Lexical access in bilingual speech production: Evidence from language switching in highly proficient bilinguals and L2 learners. Journal of Memory and Language, 50, 491511.

COSTA, Albert; COLOMÉ, Àngels; GÓMEZ, Olga; SEBASTIÁN-GALLÉS, Nuria (2003). Another look at cross-language competition in bilingual speech production: lexical and phonological factors. Bilingualism: Language and Cognition, 6 (3). Cambridge: Cambridge University Press, 167-179.

COSTA, Albert; CARAMAZZA, Alfonso; SEBASTIÁNGALLÉS, Nuria (2000). The cognate facilitation effect: Implications for models of lexical Access. Journal of Experimental Psychology: Learning, Memory and Cognition, 26 (5), 1283-1296. 
COSTA, Albert; COLOMÉ, Àngels; CARAMAZZA, Alfonso (2000). Lexical access in speech production: the bilingual case. Psicológica, 21 (2), 403-437.

COSTA, Albert; CARAMAZZA, Alfonso. Is lexical selection in bilingual speech production languagespecific? Further evidence from Spanish-English and English-Spanish bilinguals. Bilingualism: Language and Cognition, 2 (3). Cambridge: Cambridge University Press, 231-244. 1999.

COSTA, Albert; MIOZZO, Michele; CARAMAZZA, Alfonso (1999). Lexical selection in bilinguals: Do words in the bilingual's two lexicons compete for selection? Journal of Memory and Language, 41, 365-397.

EYSENCK, Michael W.; KEANE, Mark T (2007). Manual de Psicologia Cognitiva. $5^{\mathrm{a}}$ ed. Porto Alegre: Artmed.

FAN, Jin; MCCANDLISS, Bruce D.; SOMMER, Tobias; RAZ, Amir; POSNER, Michael I (2002). Testing the efficiency and independence of attentional networks. Journal of Cognitive Neuroscience, 14(3), 340-347.

FINKBEINER, Matthew; GOLLAN, Tamar H.; CARAMAZZA, Alfonso (2006). Lexical access in bilingual speakers: What's the (hard) problem? Bilingualism: Language and Cognition, 9 (2). Cambridge: Cambridge University Press, 153-166.

GREEN, David W (1998). Mental control of the bilingual lexico-semantic system. Bilingualism: Language and Cognition, 1 (2). Cambridge: Cambridge University Press, 67-81.

GROSJEAN, François (2013). Speech production. In: GROSJEAN, François; LI, Ping. The psycolinguistics of bilingualism. Oxford: Wiley-Blackwell, pp. 50-69.

HERMANS, Daan; ORMEL, E.; BESSELAAR, Ria van; HELL, Janet van (2011). Lexical activation in bilingual's speech production is dynamic: how language ambiguous words can affect cross-language activation. Language and cognition process. Cognitive neuroscience of language, 26 (10), 1687-1709.

HERMANS, Daan; BONGAERTS, Theo; DE BOT, Kees; SCHREUDER, Rodert (1998). Producing words in a foreign language: can speakers prevent interference from their first language? Bilingualism: Language and Cognition, 1 (3). Cambridge: Cambridge University Press, 213-230.

HERNÁNDEZ, Mireia; COSTA. Albert; FUENTES, Luis J.; VIVAS, Ana B.; SEBASTIÁN-GALLÉS, Nuria (2010). The impact of the bilingualism on the executive control and orienting networks of attention. Bilingualism: Language and Cognition, 13 (3). Cambridge: Cambridge University Press, 315-325.

HOSHINO, Noriko; THIERRY, Guillaume (2011). Language selection in bilingual word production: electrophysiological evidence for cross-language competition. Brain research, 1371, 100-109.

JARVIS, S.; PAVLENKO A (2008). Crosslinguistic influence in language and cognition. Mahwah, NJ: Lawrence Erlbaum.

KROLL, Judith F.; BOBB, Susan C.; MISRA, Maya; GUO, Taomei (2008). Language selection in bilingual speech: Evidence for inhibitory processes. Acta Psychologica, 1-15.

KROLL, Judith. F.; TOKOWICZ, Natasha (2005). Models of bilingual representation and processing: looking back and to the future. In: KROLL, Judith F. DE GROOT, Annette M.B. (Ed.). Handbook of bilingualism: Psycholinguistic Approaches. Oxford: Oxford University Press, pp. 531-553.

LEVELT, Willem (2000). Lexical access in speech production. In: REULAND, Eric; ABRAHAM, Werner. (eds.). Knowledge and language: from Orwell's problem to Plato's problem, 1: Springer Netherlands: Kluwer Academic Publishers, pp. 241-251.

LEVELT, Willem J. M.; ROELOFS, Ardi; MEYER, Antje S (1999). A theory of lexical access in speech production. Behavioral and brain sciences, 22. Cambridge: Cambridge University Press, 1-75.

MEUTER, Renata F. I.; ALLPORT, Alan (1999). Bilingual language switching in naming: asymmetrical costs of language selection. Journal of Memory and language, 40 (1), 25-40.

MISRA, Maya; GUO, Taomei; BOBB, Susan C.; KROLL, Judith $F$ (2012). When bilinguals choose a single word to speak: Electrophysiological evidence for inhibition of the native language. Journal of Memory and language, 67 (1), 224-237.

ODLIN, Terence (2003). Crosslinguistic influence. In: DOUGHTY, Catherine J.; LONG, Michael H. (Eds.) The Handbook of second language acquisition. Oxford: Blackwell Publishing Ltd, pp. 436-486.

ORTIZ-PREUSS, Elena (2014). Similaridade linguística entre português e espanhol: efeitos na produção de fala em L2. Revista (Con) Textos linguísticos. Vitória: PPGEL-UFES, v. 8, n. 10, p. 66-82,

. (2011). Acesso lexical e produção de fala bilíngue: o processo de seleção linguística. Organon. Porto Alegre (UFRGS), série 51, v. 26, p.81-101.

; FONTES, Ana Beatriz Arêas da Luz; FINGER, Ingrid (2015). Efeito cognato no processo de lexicalização bilíngue. Letras de Hoje, 50 (1). Porto Alegre, 73-83.

PEETERS, David. RUNNQVIST, Elin; BETRAND, Daisy; GRAINGER, Jonathan (2014). Asymmetrical switch 
costs in bilingual language production induced by reading words. Journal of experimental psychology: learning memory and cognition, 40 (1), 284-292.

POSNER, Michael I.; PETERSEN, Steven E (1990). The attention system of the human brain. Annual Review of Neuroscience, 13, 25-42.

POULISSE, Nanda; BONGAERTS, Theo (1994). First language use in second language production. Applied Linguistics, 15, 36-57.

RINGBOM, Håkan; JARVIS, Scott (2011). The importance of crosslinguistic similarity in foreign language learning. In: LONG, Michael. H.; DOUGHTY, Catherine. J. (Eds.). The Handbook of language teaching. Oxford: Blackwell Publishing Ltd, pp. 106-118.

RINGBOM, Håkan (2007). Crosslinguistic similarity in foreign language learning. Clevedon, UK: Multilingual Matters.

ROELOFS, Ardi (1998). Lemma selection without inhibition of languages in bilingual speakers. Bilingualism: Language and Cognition, 1 (2), 94-95.

SCHMIDT, Richard. Attention (2001). In: ROBINSON, P. (Ed.). Cognition and second language instruction. Cambridge: Cambridge University Press, pp. 3-32.

TOMLIN, Russel S.; VILLA, Victor (1994). Attention in cognitive science and second language acquisition. Studies in Second Language Acquisition, 16 (2), 183-203.

Recebido em: 15/02/2017 Aceito em: 05/06/2017 